\title{
Application of triethylammonium salts as ionic liquid catalyst and medium for Fischer esterification
}

\author{
Pralhad A. Ganeshpure,* Gigi George, and Jagannath Das \\ Research Centre, Indian Petrochemicals Corporation Limited, Vadodara 391 346, India \\ E-mail: Pralhad.Ganeshpure@ipcl.co.in
}

\section{This paper is dedicated to Professor Waldemar Adam on the occasion of his $\mathbf{7 0}^{\text {th }}$ birthday}

\begin{abstract}
Triethylammonium sulfate, triethylammonium dihydrogen phosphate and triethylammonium tetrafluoroborate were applied as ionic liquid catalyst and medium for the esterification of carboxylic acids with primary alcohols. Esterification of aliphatic carboxylic acids in the presence of triethylammonium sulfate gave the corresponding esters in excellent yield. The ionic liquid and ester formed separate phases in the reaction facilitating separation of the product.
\end{abstract}

Keywords: Ionic liquids, esterification, acid catalyst, triethylammonium sulfate, triethylammonium dihydrogen phosphate, triethylammonium tetrafluoroborate

\section{Introduction}

Esterification of carboxylic acids with alcohols is a reaction of industrial importance. ${ }^{1}$ Several bulk and fine chemicals are produced in this manner in chemical, petrochemical and pharmaceutical industries. The Fischer esterification is a reversible reaction which requires acid catalyst. The equilibrium is pushed to the product side by taking excess of a reactant and/or by continuously removing the water formed in the reaction. Sometimes it is necessary to employ an additional solvent to carry over the water in the form of azeotrope. Such operations require large energy input to recycle the solvents and the excess reactants. The loss of volatile organic solvents to the atmosphere results into increase in the cost of production and also damage to the environment.

Currently, ionic liquids have been receiving a lot of attention as green catalyst and medium for a variety of reactions. ${ }^{2}$ A number of Brønsted acidic ionic liquids have been reported as catalyst and also medium in the esterification reactions. ${ }^{3-13}$ The water formed in the reaction is taken up by the ionic liquid and the ester product forms a separate phase. Therefore, high conversions have been achieved by use of ionic liquids with a convenience of separation of the 
ester product from the catalyst. This is a definite advantage using ionic liquids over the homogeneous catalytic reactions where the product is separated from the catalyst by costly processes such as distillation. Use of ionic liquids, which are practically nonvolatile, obviates the need of volatile organic solvents.

The majority of the ionic liquids reported for esterification are imidazole ${ }^{3-11}$ and pyridine $7,8,13$ derivatives. Most of these are synthesized in two or more steps using expensive materials. In the present paper we report, for the first time, application of simple triethylammonium salts (1-3) as Brønsted acidic catalyst and medium for esterification of carboxylic acids with primary alcohols. The ionic liquids (1-3) are conveniently prepared in one step using inexpensive and easily available materials.

\section{$\left[\left(\mathrm{C}_{2} \mathrm{H}_{5}\right)_{3} \mathrm{NH}\right]\left[\mathrm{HSO}_{4}\right]$ \\ 1}

$\left[\left(\mathrm{C}_{2} \mathrm{H}_{5}\right)_{3} \mathrm{NH}\right]\left[\mathrm{H}_{2} \mathrm{PO}_{4}\right]$

2
$\left[\left(\mathrm{C}_{2} \mathrm{H}_{5}\right)_{3} \mathrm{NH}\right]\left[\mathrm{BF}_{4}\right]$

3

\section{Results and Discussion}

The conditions for the esterification reaction were optimized with acetic acid and 1-octanol as substrates in the presence of the ionic liquid 1. The results are shown in the Table 1 . Use of 20 mmol of both, acetic acid and 1-octanol, and $1 \mathrm{~g}$ of the salt 1 gave the corresponding ester in $77 \%$ yield (Entry 1). Use of $20 \%$ excess of alcohol resulted in $81 \%$ yield of the ester (Entry 2). Extending the reaction time to $6 \mathrm{~h}$ has practically no effect on the yield indicating that the reaction is complete in $4 \mathrm{~h}$ (Entry 3 ). Increase of the reaction temperature to $110^{\circ} \mathrm{C}$ or use of double amount of the ionic liquid has marginal effect on the yield of the ester (Entries 4 and 5). Employing 20\% excess of the acid also led to a small increase in the yield of the ester (Entry 6). However, nearly quantitative yield of $n$-octyl acetate was obtained when the alcohol to acid ratio was changed to 2 (Entry 7 ).

Application of the ionic liquid, triethylammonium dihydrogen phosphate (2) to the esterification of acetic acid with 1-octanol gave the corresponding ester in low yield (Entry 8). Similarly, triethylammonium tetrafluoroborate (3) showed poor activity under these conditions (Entry 9). The nature of the anion is known to influence the activity of ionic liquids in the esterification reaction. ${ }^{8}$ Lower acidity of anions in the ionic liquids $\mathbf{2}$ and $\mathbf{3}$ appears to be the reason for their poor activity. This was supported by the observation that the yield of the ester increased to $90 \%$ when the reaction in the entry 9 was performed after adding catalytic amount of $p$-toluenesulfonic acid (Entry 10). The ionic liquid and ester formed separate phases in all the experiments.

The ionic liquid 1 could be recycled at least two times with practically no loss of the activity. The data of recycle experiments is shown in the Table 2 . The fresh ionic liquid gave $98 \%$ yield of $n$-octyl acetate. The ionic liquid layer was separated and dried under vacuum (3-4 $\mathrm{mm})$ at $60^{\circ} \mathrm{C}$ for $3 \mathrm{~h}$. The regenerated ionic liquid was used again for the esterification. 
Table 1. Esterification of acetic acid with 1-octanol using ionic liquids 1-3

$$
\mathrm{CH}_{3} \mathrm{CO}_{2} \mathrm{H}+\mathrm{CH}_{3}\left(\mathrm{CH}_{2}\right)_{7} \mathrm{OH} \stackrel{\text { Ionic liquid }}{\rightleftharpoons} \mathrm{CH}_{3} \mathrm{CO}_{2}\left(\mathrm{CH}_{2}\right)_{7} \mathrm{CH}_{3}+\mathrm{H}_{2} \mathrm{O}
$$

\begin{tabular}{ccccccc}
\hline Entry $^{\mathrm{a}}$ & $\begin{array}{c}\text { Acetic acid } \\
(\mathrm{mmol})\end{array}$ & $\begin{array}{c}\text { 1-Octanol } \\
(\mathrm{mmol})\end{array}$ & Ionic Liquid $^{\mathrm{b}}$ & $\begin{array}{c}\text { Temp } \\
\left({ }^{\circ} \mathrm{C}\right)\end{array}$ & $\begin{array}{c}\text { Time } \\
(\mathrm{h})\end{array}$ & $\begin{array}{c}\text { Yield }^{\mathrm{c}} \text { of } \\
n \text {-octyl acetate (\%) }\end{array}$ \\
\hline 1 & 20 & 20 & $\mathbf{1}$ & 90 & 4 & 77 \\
2 & 20 & 24 & $\mathbf{1}$ & 90 & 4 & 81 \\
3 & 20 & 24 & $\mathbf{1}$ & 90 & 6 & 80 \\
4 & 20 & 24 & $\mathbf{1}$ & 110 & 4 & 84 \\
5 & 20 & 24 & $\mathbf{1}^{\mathrm{d}}$ & 90 & 4 & 84 \\
6 & 24 & 20 & $\mathbf{1}$ & 90 & 4 & 85 \\
7 & 10 & 20 & $\mathbf{1}$ & 90 & 4 & 98 \\
8 & 20 & 24 & $\mathbf{2}$ & 90 & 4 & 26 \\
9 & 20 & 24 & $\mathbf{3}$ & 90 & 4 & 18 \\
$10^{\mathrm{e}}$ & 20 & 24 & $\mathbf{3}$ & 90 & 4 & 90 \\
\hline
\end{tabular}

${ }^{\mathrm{a}}$ Reactions were performed under nitrogen atmosphere. ${ }^{\mathrm{b}} 1 \mathrm{~g}$ of ionic liquid was used. ${ }^{\mathrm{c}}$ Based on acetic acid taken. ${ }^{\mathrm{d}} 2 \mathrm{~g}$ of ionic liquid was used. ${ }^{\mathrm{e}} \mathrm{p}$-Toluenesulfonic acid (100 mg) was added.

Table 2. Recycling of the ionic liquid 1 in the esterification of acetic acid with 1 -octanol ${ }^{\mathrm{a}}$

\begin{tabular}{lc}
\hline Ionic liquid (1) & $\begin{array}{c}\text { Yield of } n \text {-octyl acetate } \\
(\%)\end{array}$ \\
\hline Fresh & 98 \\
$1^{\text {st }}$ recycle & 98 \\
$2^{\text {nd }}$ recycle & 96 \\
\hline
\end{tabular}

${ }^{\text {a }}$ Reaction conditions as in the entry 7 in the Table 1.

The ionic liquid $\mathbf{1}$ was applied to the esterification of various acids with primary alcohols. The results are shown in the Table 3. Esterification of acetic acid with 1-butanol, 1-octanol, 1dodecanol, and benzyl alcohol gave the corresponding esters in nearly quantitative yield (Entries 1-4). Similarly, esterification of butyric acid and nonanoic acid afforded their butyl esters in excellent yields (Entries 5 and 6). Acrylic acid selectively gave $n$-butyl acrylate in high yield (Entry 7). Esterification of cyclohexane carboxylic acid, benzoic acid, and $p$-hydroxybenzoic acid resulted in moderate yields of the corresponding butyl esters (Entries 8-10). In general, aliphatic carboxylic acids showed much higher reactivity in this reaction as compare to the aromatic ones. Interestingly, no separate phases were formed in the reactions involving an aromatic substrate (Entries 4, 9, 10). The standard work up procedure was applied to isolate the products in these reactions. This indicates unique solubility behaviour of the ionic liquids. 
Table 3. Esterification of various carboxylic acids with primary alcohols using ionic liquid $\mathbf{1}$

\begin{tabular}{cccc}
\hline Entry $^{\mathrm{a}}$ & Acid & Alcohol & Yield $^{\mathrm{b}}$ of ester (\%) \\
\hline 1 & $\mathrm{CH}_{3} \mathrm{CO}_{2} \mathrm{H}$ & $\mathrm{CH}_{3}\left(\mathrm{CH}_{2}\right)_{3} \mathrm{OH}$ & 97 \\
2 & $\mathrm{CH}_{3} \mathrm{CO}_{2} \mathrm{H}$ & $\mathrm{CH}_{3}\left(\mathrm{CH}_{2}\right)_{7} \mathrm{OH}$ & 98 \\
3 & $\mathrm{CH}_{3} \mathrm{CO}_{2} \mathrm{H}$ & $\mathrm{CH}_{3}\left(\mathrm{CH}_{2}\right)_{11} \mathrm{OH}$ & 99 \\
4 & $\mathrm{CH}_{3} \mathrm{CO}_{2} \mathrm{H}$ & $\mathrm{PhCH}_{2} \mathrm{OH}$ & 96 \\
5 & $\mathrm{CH}_{3}\left(\mathrm{CH}_{2}\right)_{2} \mathrm{CO}_{2} \mathrm{H}$ & $\mathrm{CH}_{3}\left(\mathrm{CH}_{2}\right)_{3} \mathrm{OH}$ & 99 \\
6 & $\mathrm{CH}_{3}\left(\mathrm{CH}_{2}\right)_{7} \mathrm{CO}_{2} \mathrm{H}$ & $\mathrm{CH}_{3}\left(\mathrm{CH}_{2}\right)_{3} \mathrm{OH}$ & 94 \\
$7^{\mathrm{c}}$ & $\mathrm{CH}_{2}=\mathrm{CH}_{-} \mathrm{CO}_{2} \mathrm{H}$ & $\mathrm{CH}_{3}\left(\mathrm{CH}_{2}\right)_{3} \mathrm{OH}$ & 91 \\
8 & $\mathrm{C}_{6} \mathrm{H}_{11} \mathrm{CO}_{2} \mathrm{H}$ & $\mathrm{CH}_{3}\left(\mathrm{CH}_{2}\right)_{3} \mathrm{OH}$ & 56 \\
9 & $\mathrm{PhCO}_{2} \mathrm{H}$ & $\mathrm{CH}_{3}\left(\mathrm{CH}_{2}\right)_{3} \mathrm{OH}$ & 56 \\
10 & $p-\mathrm{HO}-\mathrm{C}_{6} \mathrm{H}_{4}-\mathrm{CO}_{2} \mathrm{H}$ & $\mathrm{CH}_{3}\left(\mathrm{CH}_{2}\right)_{3} \mathrm{OH}$ & 63 \\
\hline
\end{tabular}

${ }^{\mathrm{a}}$ Conditions: Acid (10 mmol), alcohol $(20 \mathrm{mmol})$, ionic liquid $1(1 \mathrm{~g}), 90^{\circ} \mathrm{C}, 4 \mathrm{~h}$, under nitrogen.

b Based on acid taken. ${ }^{\mathrm{c}}$ Acrylic acid $(20 \mathrm{mmol})$ and 1-butanol $(24 \mathrm{mmol})$ were taken. Hydroquinone (15 mg) was added as a polymerization inhibitor.

We have demonstrated application of ionic liquids derived from a simple amine for the Fischer esterification to obtain the esters in high yield without use of the organic solvents and with a convenience of the product separation from the catalyst. Our efforts are directed at screening more such ionic liquids for the Fischer esterification to further understand the structure-activity relationship in this system.

\section{Experimental Section}

General Procedures. All the chemicals were of reagent grade and used as received. Melting points were determined with Sanyo Gallenkamp MPD350 apparatus and are uncorrected. The moisture content of the ionic liquids was determined with Mettler DL-18 Karl Fischer titrator. The IR spectra were recorded on Perkin-Elmer Spectrum 1 FTIR. ${ }^{1} \mathrm{H}$ NMR (300 MHz) spectra were recorded on Varian Mercury-300 spectrometer. Analysis of the reaction product was performed on a Schimadzu 15A gas chromatogram fitted with a flame ionization detector. A capillary column, Innovax, $60 \mathrm{M}$ length and $0.32 \mathrm{~mm}$ ID was used. Esters were identified by gas chromatographic comparison with their authentic samples. Quantification of the product was done by application of the GC response factors generated using the authentic samples of the esters. The ionic liquids (1-3) were prepared by the literature methods. ${ }^{14}$

Triethylammonium sulfate (1). ${ }^{14}$ Colorless solid (yield 95\%); mp 85-88 ${ }^{\circ} \mathrm{C}$ (Lit. ${ }^{14} \mathrm{mp} 91^{\circ} \mathrm{C}$ ); water content 2.6\%; IR ( $\left.\mathrm{KBr}, \mathrm{cm}^{-1}\right)$ 2959, 2923, 2670, 2489, 1470, 1425, 1398, 1227, 1057 , 
1030, 877, 850; ${ }^{1} \mathrm{H}$ NMR (300 MHz, $\left.\mathrm{CD}_{3} \mathrm{OD}\right) \delta 1.24\left(\mathrm{t}, \mathrm{J}=7 \mathrm{~Hz}, 9 \mathrm{H}, \mathrm{CH}_{3}\right), 3.13$ (q, J = $7 \mathrm{~Hz}$, $\left.6 \mathrm{H}, \mathrm{CH}_{2}\right), 5.18(\mathrm{~s}, \mathrm{NH})$.

Triethylammonium dihydrogen phosphate (2). ${ }^{14}$ Colorless solid (yield 98\%); mp 87-89 ${ }^{\circ} \mathrm{C}$ (Lit. ${ }^{14} \mathrm{mp} \mathrm{93}{ }^{\circ} \mathrm{C}$ ); water content 2.1\%; IR $\left(\mathrm{KBr}, \mathrm{cm}^{-1}\right)$ 2959, 2923, 2742, 2670, 2489, 1650, 1470, 1299, 1110, 1083, 1030, 544; ${ }^{1} \mathrm{H}$ NMR (300 MHz, CD $\mathrm{CD}_{3} \mathrm{O} \delta 1.23$ (t, J = $\left.7 \mathrm{~Hz}, 9 \mathrm{H}, \mathrm{CH}_{3}\right), 3.08$ $\left(\mathrm{q}, \mathrm{J}=7 \mathrm{~Hz}, 6 \mathrm{H}, \mathrm{CH}_{2}\right), 5.79(\mathrm{~s}, \mathrm{NH})$.

Triethylammonium tetrafluoroborate (3). ${ }^{14}$ Colorless solid (yield 96\%); mp 96-98 ${ }^{\circ} \mathrm{C}$ (Lit. ${ }^{14}$ mp $\left.98^{\circ} \mathrm{C}\right)$; water content 1.8\%; IR (KBr, cm $\left.{ }^{-1}\right) 2941,2742,2670,2489,1479,1434,1398,1173$, 1057, 1030, 841, 805; ${ }^{1} \mathrm{H}$ NMR (300 MHz, $\left.\mathrm{CDCl}_{3}\right) \delta 1.36\left(\mathrm{t}, 9 \mathrm{H}, \mathrm{CH}_{3}\right), 3.22\left(\mathrm{~m}, 6 \mathrm{H}, \mathrm{CH}_{2}\right), 7.26$ (s, NH).

Procedure for esterification reaction. A typical procedure for esterification is as follows. Acetic acid (1.2 g, $20 \mathrm{mmol}), 1$-octanol (3.12 g, $24 \mathrm{mmol})$ and ionic liquid (1 g) were taken in a round bottom flask fitted with a reflux condenser and a nitrogen balloon at the top of it. The flask was flushed with nitrogen and immersed in an oil bath. The contents of the flask were magnetically stirred and the oil bath temperature was maintained at $90^{\circ} \mathrm{C}$ for $4 \mathrm{~h}$. The reaction mixture was cooled to room temperature and the two layers separated. The top layer which contained the ester product was analyzed.

n-Octyl acetate. Colorless oil; IR $\left(\mathrm{KBr}, \mathrm{cm}^{-1}\right)$ 2923, 2851, 1739, 1461, 1362, 1236, 1038, 958, 715, 625, 607; ${ }^{1} \mathrm{H}$ NMR $\left(300 \mathrm{MHz}, \mathrm{CDCl}_{3}\right) \delta 0.88\left(\mathrm{t}, 3 \mathrm{H}, \mathrm{CH}_{3}\right), 1.27\left(\mathrm{~m}, 10 \mathrm{H},\left(\mathrm{CH}_{2}\right)\right.$ ) $), 1.59(\mathrm{~m}$, $\left.2 \mathrm{H}, \mathrm{CH}_{2}\right), 2.04\left(\mathrm{~s}, 3 \mathrm{H}, \mathrm{CH}_{3}-\mathrm{CO}\right), 4.04\left(\mathrm{t}, 2 \mathrm{H}, \mathrm{OCH}_{2}\right)$.

\section{Acknowledgement}

Gigi George thanks the management of Indian Petrochemicals Corporation Limited for the permission to work in the Research Centre.

\section{References}

1. Larock, R. C. Comprehensive Organic Transformations, VCH: New York, 1999.

2. (a) Earle, M. J.; Seddon, K. R. Pure Appl. Chem. 2000, 72, 1391. (b) Sheldon R. Chem. Commun. 2001, 2399. (c) Oliver-Bourbigou, H.; Magna, L. J. Mol. Catal. A: Chemical 2002, 182-183, 419.

3. Cole, A. C.; Jensen, J. L.; Ntai, I.; Tran, K. L. T.; Weaver, K. J.; Forbes, D. C.; Davis Jr., J. H. J. Am. Chem. Soc. 2002, 124, 5962.

4. Fraga-Dubreuil, J.; Bourahla, K.; Rahmouni, M.; Bazureau, J. P.; Hamelin, J. Catal.Commun. 2002, 3, 185.

5. Zhu, H. P.; Yang, F.; Tang, J.; He, M. Y. Green Chem. 2003, 5, 38.

6. Nguyen, H. P.; Znifeche, S.; Baboulene, M. Synth. Commun. 2004, 34, 2085. 
7. Arfan A.; Bazureau, J. P. Org. Proc. Res. \& Dev. 2005, 9, 743.

8. Xing, H.; Wang, T.; Zhou, Z.; Dai, Y. Ind. Eng. Chem. Res. 2005, 44, 4147.

9. Joseph, T.; Sahoo, S.; Halligudi, S. B. J. Mol. Catal. A: Chemical 2005, 234, 107.

10. Siddiqui, S. A. Synlett 2006, 155.

11. Zhang, Z.; Wu, W.; Han, B.; Jiang, T.; Wang, B.; Liu, Z. J. Phys. Chem.B 2005, 109, 16176.

12. Forbes, D. C.; Weaver, K. J. J. Mol. Catal. A: Chemical 2004, 214, 129.

13. Gui, J.; Cong, X.; Liu, D.; Zhang, X.; Hu, Z.; Sun, Z. Catal. Commun. 2004, 5, 473.

14. Wang, C.; Guo, L.; Li, H.; Wang, Y.; Weng, J.; Wu, L. Green Chem. 2006, 8, 603. 